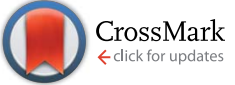

Cite this: RSC Adv., 2016, 6, 60126
Received 11th April 2016

DOI: $10.1039 / \mathrm{c} 6 \mathrm{ra09347g}$

www.rsc.org/advances
Accepted 14th June 2016

\section{Synthesis and characterization of TPGS- gemcitabine prodrug micelles for pancreatic cancer therapy $\dagger$}

\author{
Vaibhav Khare, ${ }^{\text {ab }}$ Wejdan Al. Sakarchi, ${ }^{a}$ Prem N. Gupta, ${ }^{\text {b }}$ Anthony D. M. Curtis ${ }^{a}$ \\ and Clare Hoskins*a
}

\begin{abstract}
The therapeutic potential of a nucleoside analog, gemcitabine, is severely compromised due to its rapid clearance from systemic circulation by enzymatic degradation into an inactive metabolite. In the present investigation, micelles based on polymer-drug conjugate were developed for gemcitabine and investigated for their potential to improve cancer chemotherapy. The tocopherol poly(ethylene glycol) succinate 1000 (TPGS)-gemcitabine prodrug was synthesized via an amide linkage and characterised by analytical methods, including FT-IR, ${ }^{1} \mathrm{H}$ NMR, and MALDI-TOF. The micellar formulation of TPGSgemcitabine prodrug was developed by a self-assembly technique and evaluated for various physicochemical parameters including particle size, polydispersity, morphology, critical micelle concentration and release profile. It was observed that gemcitabine present in TPGS-gemcitabine micelles was resistant to deamination by crude cytidine deaminase. The improved cytotoxicity of the micellar formulation was observed using TPGS-gemcitabine micelles against pancreatic cancer cells. Further, it was found that, unlike native gemcitabine, nucleoside transporters were not required for TPGS-Gem micelles to demonstrate their anticancer potential. These findings revealed that TPGSgemcitabine micelles may serve as a promising platform for gemcitabine in order to improve its anticancer efficacy.
\end{abstract}

\section{Introduction}

Pancreatic cancer is known as the most lethal malignant disease. ${ }^{1}$ Despite the therapeutic advances, $80-85 \%$ of cases are detected in a highly metastatic state, and complicated to treat with a median survival of $<6$ months. ${ }^{2}$ The anatomy and biology of pancreatic cancer also conspire to elude detection and resist eradication. ${ }^{3}$ Gemcitabine is a strong cytidine analog approved by the FDA for the management of pancreatic cancer and a variety of solid tumours. ${ }^{4}$ At present, gemcitabine is used as a single agent for the therapy of advanced pancreatic cancer and is the most prescribed anticancer drug worldwide, in spite of growing resistance., ${ }^{5,6}$ In recent years, several trials have demonstrated the efficacy of targeted therapy or combination chemotherapy, however, none of them has resulted in a change in the practice of gemcitabine monotherapy. ${ }^{7,8}$ Moreover, the clinical efficacy of gemcitabine is also compromised by its rapid clearance through enzymatic metabolism driven by cytidine

${ }^{a}$ Institute of Science and Technology in Medicine, Keele University, Keele, Staffordshire, ST55BJ, UK. E-mail: c.hoskins@keele.ac.uk

${ }^{b}$ Formulation and Drug Delivery Division, CSIR-Indian Institute of Integrative Medicine, Canal Road, Jammu, India 180001

$\uparrow$ Electronic supplementary information (ESI) available. See DOI: 10.1039/c6ra09347g deaminase (CDA), which is ubiquitously expressed in the liver and blood plasma., ${ }^{9,10}$ The high degree of hydrophilicity of gemcitabine further decreases its efficacy by restricting its permeation of the dense vasculature exterior of the tumour. Therefore, a high drug dose is required to achieve therapeutic concentration or desired effect, which causes serious side effects.

Many efforts have been employed to advance the efficiency of gemcitabine, including nanoparticles, ${ }^{\mathbf{1 1 , 1 2}}$ liposomes, ${ }^{\mathbf{1 3 , 1 4}}$ micelles, ${ }^{15,16}$ polymer-drug conjugates (Prodrugs). ${ }^{17,18}$ Besides other efforts, gemcitabine prodrugs received a constant recognition for its enhance metabolic stability, improved cellular uptake or cytotoxicity and to limit the resistance. Various chemically modified prodrugs of gemcitabine were reported either employing hydrophilic polymers, includes polyethylene glycol $(\mathrm{PEG})^{18}$ and poly-glutamic acid (PGA) ${ }^{19}$ or lipophilic agents such as linoleic $\operatorname{acid}^{20}$ and squalene. ${ }^{21}$ Moreover, amphiphilic polymer-drug conjugates or lipophilic prodrug conjugates are more attractive due to their self-assembling characteristics into nano-micelles upon dilution with water. Micelles, based on polymer-drug conjugate (prodrug) is an exciting development of polymeric drug delivery systems and have dual benefits arising from the polymer-drug conjugate itself as well as the properties gained from micellar formulations. Various gemcitabine formulations based on an 
amphiphilic polymers or lipid-based micelles have been reported to possess improved efficacy of gemcitabine. Chitkara et $a .^{22}$ reported gemcitabine conjugated poly(ethylene glycol)block-poly(2-methyl-2-carboxyl-propylenecarbonate) (PEG-PCC) self-assembled micelles improves plasma stability and in vivo efficacy of gemcitabine against MiaPaCa-2 cells derived xenograft tumour in mice. In another study, Daman et al. ${ }^{15}$ compared the in vitro efficacy of 4 - $(N)$-stearoyl gemcitabine (GemC18) loaded PEG-PLGA micelles and 4- $(N)$-stearoyl gemcitabine self-assembled micelles against pancreatic cancer and reported the higher efficacy of self-assembled $4-(N)$-stearoyl gemcitabine micelles. Recently, Han et al. ${ }^{23}$ demonstrated the high cytotoxicity of gemcitabine conjugated PEG- $b$-[PLA-coPMAC-graft-(IR820-co-GEM)] self-assembled theranostic micelles in BxPC-3 cells and higher accumulation in the tumour tissue.

To extend this concept of self-assembled micelles based on amphiphilic polymer-drug conjugate, in the present investigation, we have designed a gemcitabine prodrug in which drug is conjugated with such amphiphilic polymer, which possesses additional therapeutic values. D-Alpha-tocopherol polyethylene glycol succinate (TPGS) was used as an amphiphilic polymer to synthesize gemcitabine prodrug. TPGS is an amphiphilic derivative of natural vitamin $\mathrm{E}$ ( $\alpha$-tocopherol), synthesized by grafting $\alpha$-tocopherol with polyethylene glycol oligomer via a succinate linker and gained interest in the development of drug delivery systems. ${ }^{24}$ TPGS has been permitted by FDA as a drug solubiliser, in a variety of formulations and listed as a GRAS (generally referred as safe) supplement, also used as an absorption enhancer and stabiliser. ${ }^{25,26}$ It has been reported that TPGS acts as an anticancer agent alone or synergistically with chemotherapeutic drugs. ${ }^{27-31}$ Recently, Neophytou et al. investigated that the intrinsic anticancer activity of TPGS is due to the inhibition of phospho-AKT and the downregulation of the anti-apoptotic proteins survivin and Bcl-2. ${ }^{27}$ In addition, it has been reported that the inhibition of survivin expression in pancreatic cancer could potentiate the activity of gemcitabine significantly. ${ }^{32,33}$

Previously we have investigated the potential of poly(lactideco-glycolide)-gemcitabine prodrug conjugate in an attempt to improve the efficacy of gemcitabine. ${ }^{17}$ In this work, we synthesized TPGS-gemcitabine (TPGS-Gem) prodrug to protect the drug from enzymatic metabolism. The TPGS-Gem prodrug was characterized for self-assembly properties to explore their potential as drug delivery carrier for improved efficacy of gemcitabine.

\section{Experimental}

\subsection{Materials}

Gemcitabine was purchased from Fluorochem (UK). Tocopherol poly(ethylene glycol) succinate 1000, dimethylamino pyridine, succinic anhydride, $N$-hydroxysuccinimide (NHS), $N, N^{\prime}$-dicyclohexyl carbodiimide (DCC), dry dichloromethane, diethyl ether and ethanol were purchased from Sigma-Aldrich (UK). MTT (3(4,5-dimethylthiazol-2-yl)-2,5-diphenyltetrazolium bromide) was purchased from Santa Cruz Biotechnology (Santa Cruz, CA).
Recombinant human cytidine deaminase (specific activity 3.5 unit per mg) was obtained from ProSpec (USA). The human pancreatic cancer cells (BxPC-3) were procured from European Collection of Cell Cultures (ECACC, LGC Standards, UK) and grown in complete growth medium, Roswell Park Memorial Institute medium (RPMI) supplemented with 10\% fetal bovine serum and $1 \%$ penicillin streptomycin procured from Gibco BRL (Life Technologies, UK).

\subsection{Synthesis of TPGS-gemcitabine prodrug}

The TPGS-Gem prodrug was synthesized in a two-step process. The first step involves functionalization of TPGS with the terminal free carboxyl group by esterification through succinic anhydride (SA) and a catalytic amount of dimethylamino pyridine (DMAP). ${ }^{34}$ Subsequently, the second step involves the amidation of an amino group on gemcitabine with functionalised carboxyl group of TPGS. The schematic illustration of the synthetic route is shown in Fig. 1. In brief, TPGS (1 equivalent), succinic anhydride ( 2 equivalent), and dimethylamino pyridine (1 equivalent) were dissolved in dry dichloromethane (DCM) and reacted under a nitrogen atmosphere for $24 \mathrm{~h}$ at room temperature (RT). The reaction mixture was filtered and precipitated in cold diethyl ether and dried under vacuum. The precipitated product was taken up in DCM and dialyzed (Pur-ALyzer dialysis kit, MWCO 1000, Sigma) against 50 : 50 mixture of ethanol : water for $72 \mathrm{~h}$ to remove excess amount of DMAP and SA. The TPGS-SA was dried under vacuum and stored at $-20{ }^{\circ} \mathrm{C}$ until further use.

The conjugation of the amino group of gemcitabine and carboxyl group of TPGS-SA was achieved by classical carbodiimide coupling reaction. In brief, TPGS-SA ( 1 equivalent), dicyclo hexyl carbodiimide (DCC, 2 equivalent), $N$-hydroxysuccinimide (NHS, 2 equivalent) was dissolved in anhydrous DMSO and reacted for $24 \mathrm{~h}$ at RT under nitrogen conditions. The reaction was filtered using $0.45 \mu \mathrm{m}$ syringe filter, to remove the by-product $N, N$-dicyclohexylurea. The filtrate was mixed with a solution containing gemcitabine ( 2 equivalent of TPGSSA) and triethylamine (2 equivalent) in DMSO and kept under stirring for further $24 \mathrm{~h}$ in a nitrogen environment at RT. The reaction mixture was dialysed (Pur-A-Lyzer dialysis kit, MWCO 1000, Sigma) against DMSO to remove unreacted gemcitabine for $24 \mathrm{~h}$. Afterward, the dialyzing media was replaced by water to remove DMSO and reaction mixture was freeze-dried to obtain TPGS-Gem prodrug.

\subsection{Characterization of TPGS-gemcitabine prodrug}

The conjugation between TPGS and gemcitabine was validated by different analytical methods including Fourier transform infrared (FT-IR) spectroscopy and nuclear magnetic resonance (NMR) spectroscopy and MALDI-TOF spectroscopy. The FT-IR spectra for TPGS, TPGS-SA gemcitabine and TPGS-Gem prodrug were recorded from Perkin Elmer, FT-IR spectrometer. Neat samples were analyzed to detect IR bands over a range $3500-800 \mathrm{~cm}^{-1} .{ }^{1} \mathrm{H}$ NMR spectrum of native gemcitabine, TPGS, TPGS-SA, and TPGS-Gem, were acquired on a Bruker DRX 300 MHz NMR spectrometer. Tetramethylsilane was used as an 
<smiles>Cc1c(C)c2c(c(C)c1OC(=O)CCC(=O)OC(C)(C)COC(C)(C)C)CCC(C)(CCCC(C)(C)C)O2</smiles>

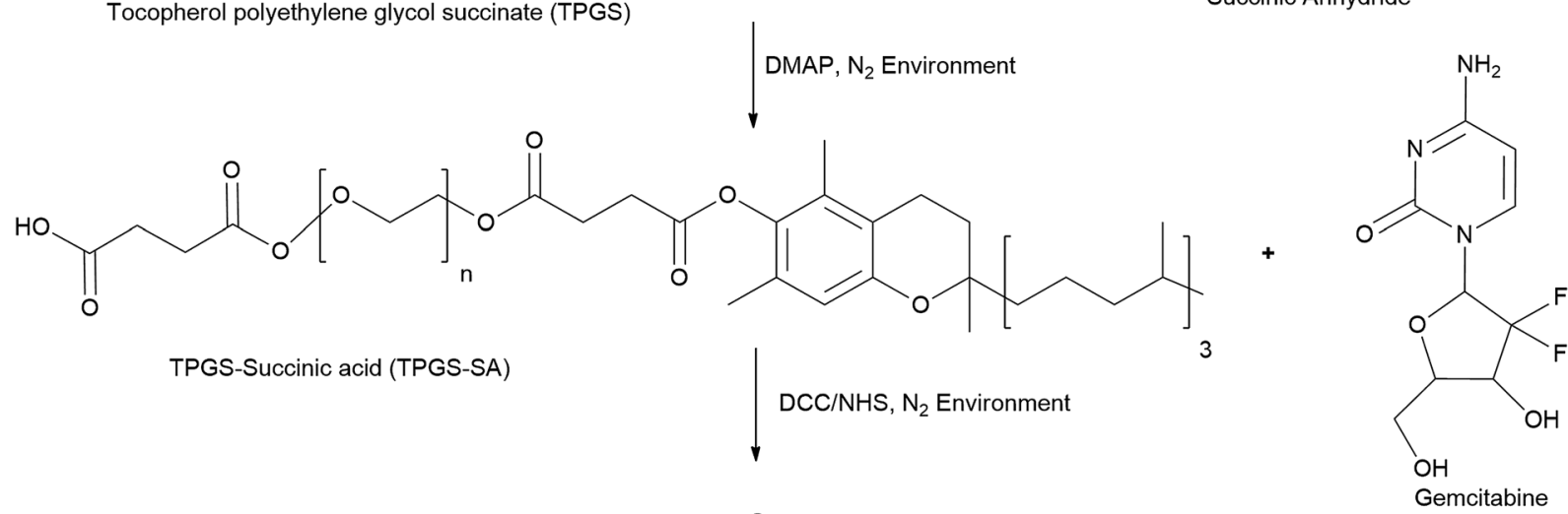<smiles>CC(=N)NOC(=O)CCC(=O)OC(C)(C)COC(C)(C)OC(=O)CCC(=O)Oc1c(C)cc2c(c1C)CCC(C)(CCCC(C)(C)C)O2</smiles><smiles>O=c1ncccn1C1OC(CO)C(O)C1(F)F</smiles>

TPGS-Gemcitabine

Fig. 1 A schematic representation of the reaction involved in the synthesis of tocopherol polyethylene glycol succinate 1000 (TPGS)-gemcitabine prodrug.

internal standard. A mass spectrum of native TPGS, TPGS-SA, and TPGS-Gem were obtained by MALDI-TOF (Applied Biosystems/AB Sciex) equipped with ND-YAG diode pump laser $(355 \mathrm{~nm} / 200 \mathrm{~Hz}$ ). The instrument was run in a positive ion reflection mode using CHCA (a-cyano- $p$-hydroxycinnamic acid) as a matrix. Respective peptide standards were used to calibrate the mass range. The spectra were recorded in the range of 800 to 2400 Da.

\subsection{RP-HPLC analysis}

The content of gemcitabine conjugated to TPGS-gemcitabine prodrug was determined using RP-HPLC method. ${ }^{35}$ Alkaline hydrolysis was performed in $\mathrm{KOH} 0.1 \mathrm{~N}$ to separate the native gemcitabine from TPGS moiety. In brief, $1 \mathrm{mg} \mathrm{ml}{ }^{-1}$ concentration of TPGS-Gem was incubated with $0.1 \mathrm{~N}$ of $\mathrm{KOH}$ at $40{ }^{\circ} \mathrm{C}$ for $1 \mathrm{~h}$. Samples were appropriately diluted with acetonitrile and the amount of gemcitabine quantified by HPLC (Perkin Elmer) analysis. The samples were analyzed using HPLC equipped with RP-18 column (E-Merck, $5 \mu \mathrm{m}, 4.0 \times 250 \mathrm{~mm}$ ) with PDA detector. Acetonitrile and $0.02 \mathrm{M}$ ammonium acetate buffer $(1: 1)$ was used as mobile phase at flow rate $0.5 \mathrm{ml} \mathrm{min} \mathrm{m}^{-1}$. The detection wavelength $\left(\lambda_{\max }\right)$ for gemcitabine was $268 \mathrm{~nm}$ and retention time of gemcitabine was found to be $4.08 \mathrm{~min}$.

\subsection{Preparation of TPGS-gemcitabine prodrug micelles}

TPGS-Gem prodrug micelle was prepared by a simple solvent evaporation method with minor modifications. ${ }^{36}$ Briefly, $30 \mathrm{mg}$ of TPGS-Gem prodrug was solubilized in $1.5 \mathrm{ml}$ of ethanol and added drop-wise to $15 \mathrm{ml}$ of ultra-purified water under stirring. The solution was stirred gently on magnetic stirrer to evaporate organic solvent. The resultant mixture was filtered by $0.45 \mu \mathrm{m}$ poly(ethersulfone) syringe filter. For storage, the micelles were freeze dried and kept refrigerated until further use.

\subsection{Micelles characterization}

The average particle size, size distribution, polydispersity index (PDI) and surface charge of prepared micelles were determined through dynamic light scattering (DLS) (Zetasizer, ZS-Nano, 
Malvern, UK). The particle size measurement was performed using disposable poly(styrene) cells, the micelle solution was incubated at various temperatures $\left(25-40{ }^{\circ} \mathrm{C}\right)$ for $10 \mathrm{~min}$ to attain the equilibrium. The zeta potential of micelles solution was measured using plain folded zeta cells, at $25{ }^{\circ} \mathrm{C}$ on fixed scattered light at an angle $90^{\circ}$. All measurements were performed in triplicate. The morphological investigation of prepared micelles was performed using JEOL JEM-1230 transmission electron microscope (JEOL, Japan). A drop of the micellar formulation was carefully placed on the formvarcoated copper grid (200 mesh) and then dried at room temperature overnight before observation on the microscope.

\subsection{Critical micelle concentration using UV hydrophobic probes}

The critical micelle concentration (CMC) of TPGS-Gem prodrug was investigated by UV hydrophobic probe, methyl orange, as described by Uchegbu et al. ${ }^{37}$ In brief, a methyl orange $(25 \mu \mathrm{M})$ stock solution was prepared using sodium tetraborate buffer $(0.02 \mathrm{M}, \mathrm{pH} 9.4)$ in deionised water. A solution of $10 \mathrm{mg} \mathrm{ml}^{-1}$ concentration of TPGS-Gem prodrug was prepared in methyl orange solution. Various concentration $\left(0.015-2.5 \mathrm{mg} \mathrm{ml}^{-1}\right)$ of TPGS-Gem was prepared by serial dilution of prodrug solution using methyl orange stock as diluent. Each concentration was scanned in the UV-visible spectrophotometer (UV-2600, Shimadzu) between 350 and $600 \mathrm{~nm}$ and maximum absorbance $\left(\lambda_{\max }\right)$ was registered. The $\lambda_{\max }$ of aqueous methyl orange stock solution was recorded as control (i.e. $0 \mathrm{mg} \mathrm{ml}^{-1}$ surfactant). A graph was plotted between $\lambda_{\max } v s$. surfactant concentration. The CMC is identified as the inflection point (hypsochromic shift) at the beginning of the curve on the graph plotted against $\lambda_{\max } v s$. TPGS-Gem concentration.

\subsection{In vitro drug release}

In vitro drug release study of TPGS-Gem micelles was performed in buffer solution with $\mathrm{pH} 7.4$ at various temperatures i.e. 30, 37 and $40{ }^{\circ} \mathrm{C}$. In brief, $3 \mathrm{ml}$ of TPGS-Gem micelle solution was placed in a dialysis bag (MWCO 1000) and immersed with $20 \mathrm{ml}$ of buffer solutions in a shaker incubator at temperature 30, 37 and $40{ }^{\circ} \mathrm{C}$. At scheduled time intervals, $100 \mu \mathrm{l}$ of the sample was collected from buffer solution and replaced with the same amount of fresh buffer of the same temperature. The collected samples were analyzed by validated RP-HPLC method reported above. Experiments were performed in triplicates for up to one week.

\subsection{Stability studies with cytidine deaminase}

The TPGS-Gem micelles and native gemcitabine were exposed to cytidine deaminase, in order to evaluate the metabolism triggered by the enzyme. Briefly, $0.4 \mathrm{mM}$ concentration of TPGS-Gem micelles and gemcitabine were prepared in $0.1 \mathrm{M}$ Tris buffer ( $\mathrm{pH} 7.5$ ) with respect to gemcitabine concentration. The reactions were initiated by addition of $10 \mu \mathrm{l}$ of recombinant human cytidine deaminase, dissolved $20 \mathrm{mM}$ Tris-buffer, $2 \mathrm{mM}$ EDTA and $40 \%$ glycerol in $1 \mathrm{ml}$ of each solution. At various time points, $60 \mu \mathrm{l}$ of aliquots were collected mixed with $30 \mu \mathrm{l}$ of acetonitrile to terminate the enzyme activities. The solvent of the reaction mixture was evaporated using freeze drying. The dried sample was reconstituted in $100 \mu$ of water and analyzed by LC-MS/MS using the method described in our previous report. $^{17}$

\subsection{Cell culture methods}

BxPC-3 cells were cultured using RPMI medium supplemented with $10 \%$ fetal bovine serum (FBS) and 1\% antibiotic (streptomycin and penicillin) solution in $50 \mathrm{ml}$ cell culture flask. Cells were cultivated in a humidified incubator with 5\% carbon dioxide at $37{ }^{\circ} \mathrm{C}$. After $90 \%$ confluence level reached, cells were routinely trypsinised and subcultured.

\subsection{In vitro cytotoxicity}

For evaluation of the cytotoxic potential of TPGS-Gem micelles, MTT assay was performed in comparison with gemcitabine and placebo TPGS micelles (i.e. TPGS micelles with no drug conjugated, in equivalent weight as in TPGS-Gem micelles) at incubation time $24 \mathrm{~h}, 48 \mathrm{~h}$, and $72 \mathrm{~h}$. BxPC-3 cells were seeded for 24 $\mathrm{h}$ in 96 well flat bottom plates (Corning, USA) at a density of 15 $\times 10^{3}$ cells per well in RPMI medium. Various concentrations of test samples were added to the cells and incubated for predetermined time intervals. After completion of the incubation period, the medium was replaced with $100 \mu \mathrm{l}$ of MTT dye to each well at $0.5 \mathrm{mg} \mathrm{ml}^{-1}$ concentration and incubated for $4 \mathrm{~h}$. The degree of cell viability is expressed by translation of MTT into purple formazan crystals by metabolically viable cells. The produced formazan crystals were dissolved using $100 \mu \mathrm{l}$ of DMSO and optical density of wells was measured at wavelength $570 \mathrm{~nm}$ spectrophotometrically (BioTek, Synergy HT). The nonlinear regression analysis was performed to determine a concentration caused a $50 \%$ inhibition in the control growth rate $\left(\mathrm{IC}_{50}\right)$ using Graph Pad software.

\subsection{Nucleoside transporter inhibition}

Gemcitabine typically enters across the cellular membrane through nucleoside transporter (hENT and/or hCNT).$^{38}$ Since one or more of these nucleoside transporters are essential for gemcitabine to enter the cell, we performed a nucleoside transporter inhibition assay, to investigate whether TPGS-Gem micelles also dependent on nucleoside transporter. The MTT assay was performed as mentioned above with minor changes. BxPC-3 cell suspension was seeded in 96 well flat bottom plates and incubated for $24 \mathrm{~h}$. A $10 \mu \mathrm{M}$ concentration of dipyridamole (a nucleoside transporter inhibitor) was incubated with cells prior to sample addition to inhibiting the hENT-1 transporter. The $\mathrm{IC}_{50}$ values were calculated to determine the effect of inhibition of nucleoside transporters.

\subsection{Cellular uptake}

A cellular uptake study was performed to demonstrate the internalization of TPGS-Gem micelles in the presence and absence of nucleoside transporter inhibitor, dipyridamole. Coumarin-6 loaded TPGS-Gem micelles was prepared by same 
method as described for TPGS-Gem micelles, except that coumarin-6 was added in first step with the prodrug in ethanol. BxPC-3 cells were seeded onto a borosilicate glass cover slip in six well plates for $24 \mathrm{~h}$. Then the media of three wells was replaced with a $10 \mu \mathrm{M}$ concentration of dipyridamole to inhibit the nucleoside transporters, $30 \mathrm{~min}$ before the addition of test samples. Afterwards the media of all six wells was substituted with $0.125 \mathrm{mg} \mathrm{ml}^{-1}$ of coumarin-6 loaded TPGS-Gem micelles and incubated for $4 \mathrm{~h}$ at $37{ }^{\circ} \mathrm{C}$ in $\mathrm{CO}_{2}$ incubator. After completion of incubation time the cells were washed twice by PBS (pH 7.4) and fixed with 70\% ethanol and the nuclei was counter stained by DAPI (4,6 diamidino-2-phenyl indole). Then the cells were observed under fluorescence cell imaging station (EVOS FLoid).

\subsection{AFM topography}

The effect of morphological changes was assessed after treatment with TPGS-Gem micelles, gemcitabine, and native TPGS using atomic force microscope after $24 \mathrm{~h}$ of incubation. BxPC-3 cells were seeded in 6 well plates over coverslips. Cells were incubated in a humidified incubator at $37{ }^{\circ} \mathrm{C}$ and $5 \% \mathrm{CO}_{2}$ atmosphere. After $24 \mathrm{~h}$, the media was replaced with a $10 \mu \mathrm{M}$. The concentration of gemcitabine and TPGS-Gem micelles dissolved in media and incubated for $24 \mathrm{~h}$. The control cells were treated with media only. Afterward, the media was removed and cells were washed abundantly with PBS and fixed using 2.5\% solution of glutaraldehyde prepared in PBS for 10 min. After fixation cells were again washed 5-6 times with PBS and mounted on a glass slide. Cell topography was imaged using a Bruker Bio Catalyst atomic force microscope (Bruker, Germany) using Peak Force Tapping Mode and a Scan Asyst in air cantilever.

\section{Results and discussion}

The TPGS-Gem micelle was prepared after synthesis of TPGSGem prodrug. The gemcitabine was conjugated to TPGS through a succinate linker as a two-step process: (I) modification of end group of TPGS to a carboxylic group using succinic anhydride and (II) coupling of activated ester form of succinic acid-modified TPGS to the amino group of gemcitabine using classical carbodiimide chemistry, as shown in Fig. 1. All the reactions performed to synthesize TPGS-Gem prodrug were characterized by different analytical techniques including FTIR, ${ }^{1} \mathrm{H}$ NMR, and MALDI-TOF.

\subsection{Characterization of TPGS-Gem prodrug}

3.1.1 Fourier transform infrared spectra. The FT-IR spectra of native TPGS (Fig. 2) showed a characteristic band on 1736 $\mathrm{cm}^{-1}$ is attributed to the carbonyl group present in the TPGS. In the FT-IR spectra of TPGS-SA the strong absorption of carbonyl band at $1732 \mathrm{~cm}^{-1}$ was observed, which confirmed the formation of TPGS-SA, these findings are in accordance with previous reports. ${ }^{34,39}$ Moreover, in the FT-IR spectra of gemcitabine, the band found at $1674 \mathrm{~cm}^{-1}$ and $1662 \mathrm{~cm}^{-1}$ attributed as a characteristic amine bending vibrations. In contrast, the FT-IR spectra of TPGS-Gem prodrug showed the characteristic

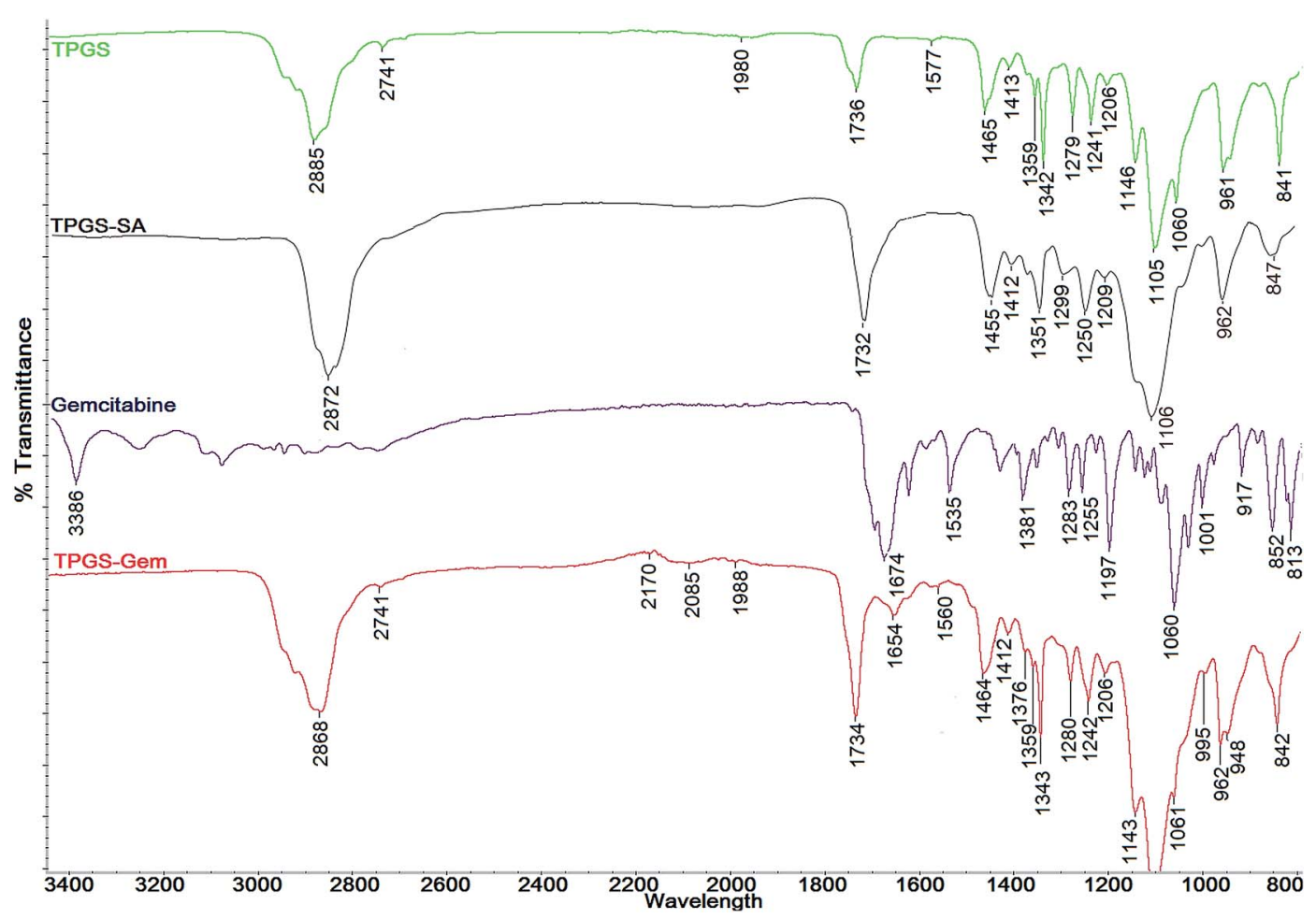

Fig. 2 Stacked Fourier transform-infrared (FT-IR) spectra of TPGS, gemcitabine and TPGS-Gem prodrug scanned in the region of $3500 \mathrm{~cm}^{-1}$ to $800 \mathrm{~cm}^{-1}$ 
carbonyl band at $1734 \mathrm{~cm}^{-1}$, in addition, bands at $1654 \mathrm{~cm}^{-1}$ and $1560 \mathrm{~cm}^{-1}$ represents amide $\mathrm{I}(\mathrm{C}=\mathrm{O}$, stretching $)$ and amide II ( $\mathrm{N}-\mathrm{H}$ bending), respectively, confirmed the formation of amide bond between terminal carboxyl group of TPGS and primary amino group of gemcitabine. ${ }^{17}$

3.1.2 Nuclear magnetic resonance spectroscopy. The structure of TPGS-Gem prodrug was also corroborated by ${ }^{1} \mathrm{H}$ NMR spectra (Fig. 3). In the ${ }^{1} \mathrm{H}$ NMR spectrum of TPGS, the signals of ethylene protons of PEG chain, present in TPGS were observed at $\delta$ 3.5-3.6. The signals registered in the aliphatic region $(\delta 1-3)$ of spectra attributed to the various protons of vitamin E-tail. ${ }^{1} \mathrm{H}$ NMR spectra of TPGS-SA showed similar signals as observed in the spectra of TPGS except succinyl methylene $\left(-\mathrm{CH}_{2}\right)$ protons at $\delta 2.6-2.7$, confirmed the reaction between TPGS and succinic anhydride. ${ }^{34}$ In the ${ }^{1} \mathrm{H}$ NMR spectrum of gemcitabine, peaks at $\delta 8.2$ correspond to the protons of a 4-amino group of gemcitabine. Other characteristic signals of $5^{\prime}$ and $3^{\prime} \mathrm{OH}$ of gemcitabine was registered at $\delta 6.08$ and 6.28 respectively. ${ }^{20}$ The ${ }^{1} \mathrm{H}$ NMR spectra of TPGS-Gem prodrug showed the characteristic ethylene protons of PEG chain at $\delta 3.5$ with various protons of vitamin E-tail. However, the peak of the amino group of gemcitabine was shifted from $\delta 8.2$ to $\delta 11.2$ suggested the formation of an amide bond between gemcitabine and TPGS. ${ }^{20,40}$

3.1.3 MALDI-TOF mass spectroscopy. The MALDI-TOF spectra of TPGS, TPGS-SA and TPGS-Gem was investigated to assign the formula of various oligomeric compositions with different adduct and charge states (Fig. 4). The molecular formula of TPGS forming potassium adduct was validated as $\mathrm{C}_{33} \mathrm{H}_{54} \mathrm{O}_{5}-\left(\mathrm{CH}_{2} \mathrm{CH}_{2} \mathrm{O}\right)_{n}+\mathrm{K}$. In the MALDI spectrum of TPGS-SA, a marked $100 \mathrm{Da}$ increment in the mass of various oligomers was observed, which is equal to the mass of succinic anhydride, suggesting the reaction between TPGS and succinic anhydride. An expected empirical formula for various oligomers of TPGSSA forming potassium adduct could be $\left[\mathrm{C}_{33} \mathrm{H}_{53} \mathrm{O}_{5}-\left(\mathrm{CH}_{2} \mathrm{CH}_{2}\right.\right.$ $\left.\mathrm{O})_{n}\right]-\mathrm{CO}-\mathrm{C}_{2} \mathrm{H}_{4}-\mathrm{COOH}+\mathrm{K}$. Moreover, the MALDI spectra of TPGS-Gem prodrug showed an increment of 245 Da in oligomeric clusters as compared to the oligomers of TPGS-SA, which is similar to the increment of mass if gemcitabine conjugated to TPGS-SA via an amide bond. However, there was no adduct (including $\mathrm{K}, \mathrm{Na}$ ) seen in the oligomeric clusters of TPGS-Gem spectra. Furthermore, in the spectra of TPGS and TPGS-SA the oligomers presents in different charge state.

For instance, the reaction between TPGS oligomer with $n$ value 20, $\left[\mathrm{C}_{33} \mathrm{H}_{54} \mathrm{O}_{5}-\left(\mathrm{CH}_{2} \mathrm{CH}_{2} \mathrm{O}\right)_{20}, 1411 \mathrm{Da}\right.$; or $\mathrm{m} / z 1450$ in the potassium salt form] occurs with succinic acid would lead to the species at $\mathrm{m} / \mathrm{z} 1511$ (or $\mathrm{m} / \mathrm{z} 1550$ in the form of potassium salt) and further reaction with gemcitabine would lead to the species at 1757 (with no adduct formation). By comparing the spectra of TPGS, TPGS-SA and TPGS-Gem an increment of the abundance of the ion at 1550 in TPGS-SA and 1757 in the spectra of TPGS-Gem is clearly visible, confirmed the

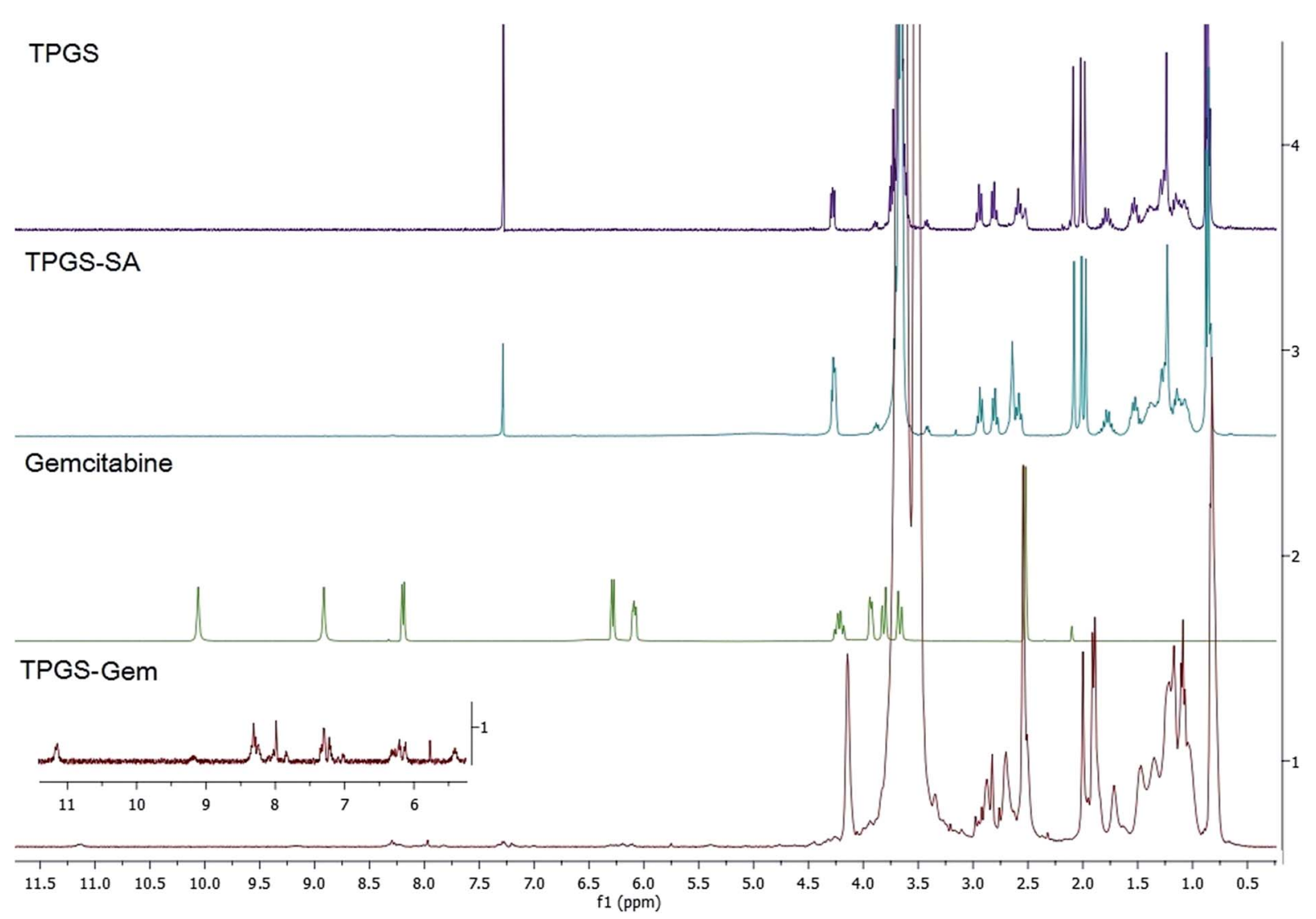

Fig. 3 Stacked ${ }^{1} \mathrm{H}$ NMR (400 MHz) spectra of TPGS, TPGS-SA, gemcitabine, and TPGS-Gem micelles registered using trimethylsilane as an internal standard. 


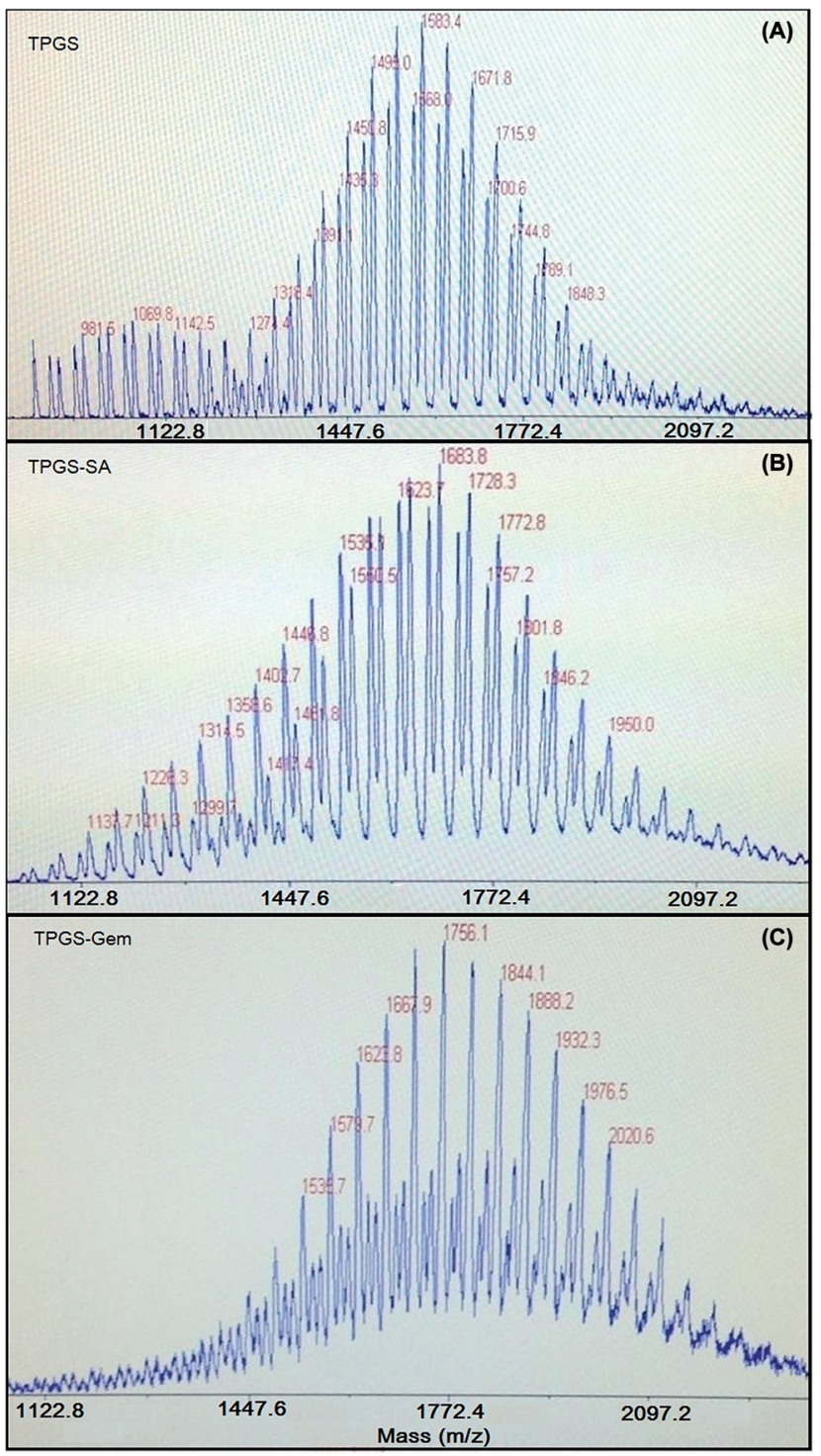

Fig. 4 Full mass overview spectra's of TPGS (A), TPGS-SA (B) and TPGS-Gem prodrug (C) by MALDI-TOF.

transformation of the terminal hydroxyl group to the carboxyl group at TPGS terminal end after I step of reaction and formation of an amide bond between TPGS-SA and gemcitabine after II step. The similar behavior was noticed for all other oligomeric species. The concise table of proposed formulas of oligomeric compositions of TPGS-Gem prodrug and intermediates is given in ESI. $\dagger$ The conjugation of gemcitabine to TPGS is an important consideration since gemcitabine as a hydrophilic drug have very low encapsulation efficiency in polymeric nanoparticles. TPGS-Gem micelles could be used as a new strategy to deliver hydrophilic drug if the loading efficiency is high. The amount of drug conjugated to TPGS was calculated to be $36.3 \pm 2.5 \mu \mathrm{g} \mathrm{mg}^{-1}$ of TPGS-Gem prodrug, which is higher than our previous investigation (i.e. $0.124 \mathrm{~mol}$ of gemcitabine per mol of PLGA) in which an antiproliferative activity of PLGA-gemcitabine polymeric conjugate was demonstrated. ${ }^{17}$
3.1.4 Micelle generation and characterization. The TPGSGem micelles were generated by simple solvent evaporation method as described above. The amphiphilic TPGS-Gem prodrug generates micelles by self-assembly in aqueous solution. After evaporation of the solvent, the generated micelles were characterised using various physicochemical parameters.

3.1.5 Particle size, zeta-potential and morphological analysis. The average particle diameter of TPGS-Gem prodrug was investigated upon nano-aggregation into micelles at different temperatures $\left(25,30,35,40^{\circ} \mathrm{C}\right)$. No significant alteration was observed in the hydrodynamic diameter at selected temperatures, suggested that temperature does not influence the average particle size of micelles. An average particle size at 25 ${ }^{\circ} \mathrm{C}$ was measured as $15.09 \pm 0.7 \mathrm{~nm}$ (Fig. 5A) with polydispersity index, $0.078 \pm 0.025$. Further at higher temperature the change in size of TPGS-Gem micelles has been observed to be negligible and the average hydrodynamic was registered as $15.67 \pm 0.16,15.38 \pm 0.34,15.94 \pm 0.59$ and PDI $0.19 \pm 0.02$, $0.115 \pm 0.037,0.153 \pm 0.032$ respectively, at temperature 30 ${ }^{\circ} \mathrm{C}, 35{ }^{\circ} \mathrm{C}$ and $40{ }^{\circ} \mathrm{C}$. The zeta potential of the micelles was evaluated as $-9.3 \pm 0.61 \mathrm{mV}$ (Fig. 5B). Particle size and zeta potential are the key factors for achieving the therapeutic efficacy of nanomedicines and micelles typically between 10 $\mathrm{nm}$ and $100 \mathrm{~nm}$ are known to be favorable for drug delivery in cancer therapy. ${ }^{41}$ Particles smaller than $10 \mathrm{~nm}$ in size will be rapidly abolished through renal clearance (threshold $<6 \mathrm{~nm}$ ) and greater than $100 \mathrm{~nm}$, have a probability to uptake by reticuloendothelial system (RES). ${ }^{42}$ Moreover, either neutral or anionic surface charge is considered beneficial for nanocarriers for successful evasion of renal elimination could result long circulatory action in vivo. ${ }^{43}$ The transmission electron microscopy (TEM) was used to determine the morphology of TPGS-Gem micelles; from which it can be seen that micelles have generally spherical shape (Fig. 5C), however, a slightly bigger than the particle size was observed with DLS. The difference in the size obtained by two techniques could be due to the melting property of TPGS (melting point $-38^{\circ} \mathrm{C}$ ). The micelles experience a certain extent of melting and expansion in size due to a high energy electron beam in TEM which makes them appear bigger in the images captured by TEM. ${ }^{44}$

3.1.6 Critical micelle concentration. The CMC value of TPGS-Gem prodrug and native TPGS was investigated using methyl orange as a hydrophobic probe in aqueous solution by monitoring the hypsochromic shift in methyl orange UV spectra (Fig. 5D). Methyl orange has $\lambda_{\max }$ at $464 \mathrm{~nm}$ in the presence of UV light. When a surfactant was diluted in methyl orange solution, it favours the hydrophobic core formed from the micelles of the amphiphilic polymers and a hypsochromic shift was experienced at critical micelle concentration value on UV spectra of amphiphilic polymer or surfactant. ${ }^{45}$ The effect of concentration of TPGS-Gem prodrug on the peak absorption of methyl orange at $\lambda_{\max } 464 \mathrm{~nm}$ is given in the Fig. 5D. The native TPGS exhibited the CMC value at $0.2 \mathrm{mg} \mathrm{m}^{-1}(0.02 \%)^{39,46}$ and it was observed that the CMC value of TPGS-Gem prodrug was $0.15 \mathrm{mg} \mathrm{ml}^{-1}(0.015 \%)$. The lower CMC value of micelles 


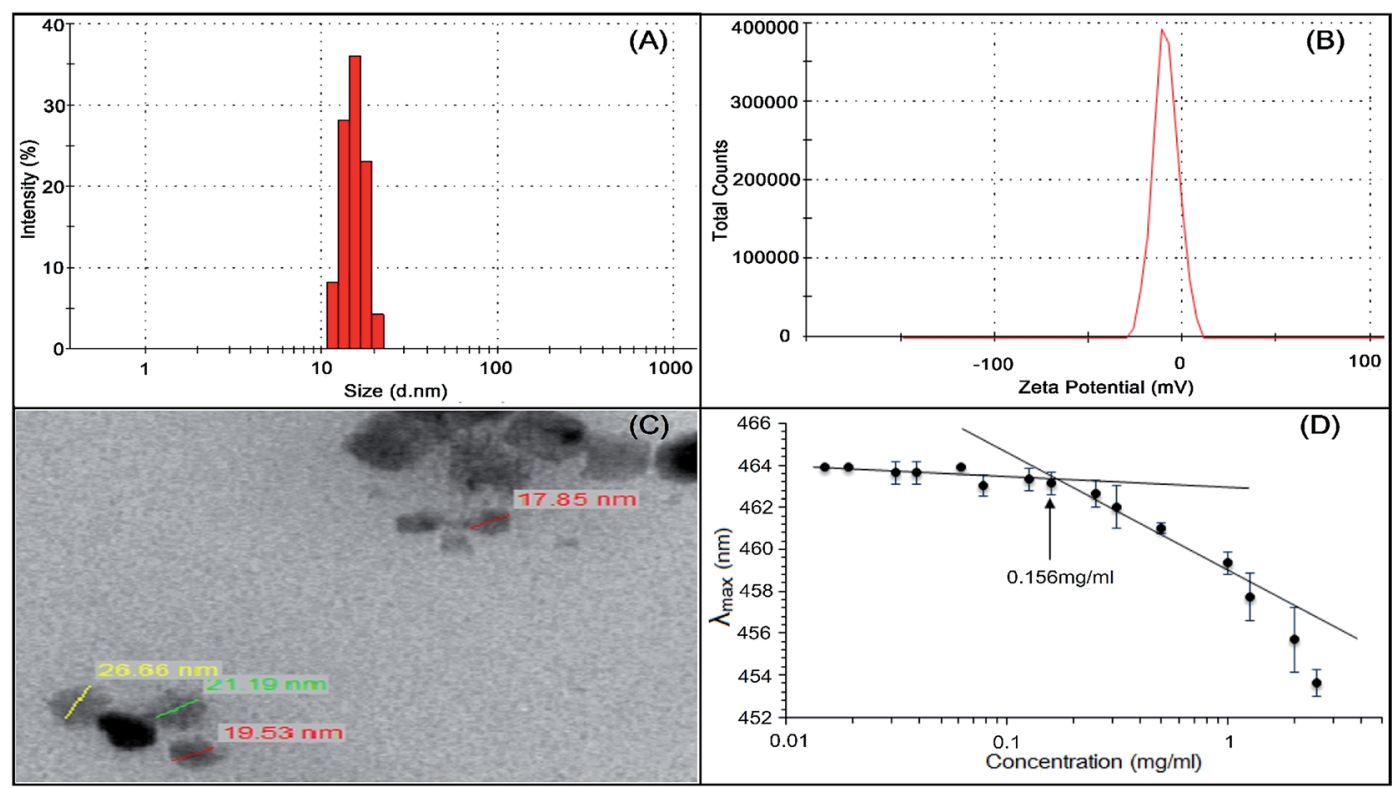

Fig. 5 Representative particle size distribution (A) and zeta potential (B) of TPGS-Gem micelles measured by dynamic light scattering measurement at fixed $90^{\circ}$ angle at $25^{\circ} \mathrm{C}$ using disposable polystyrene cells and folded capillary cells respectively. (C) Transmission electron micrograph of TPGS-Gem micelles revealing size of micelles captured using a formvar-coated copper grid (D). Critical micelle concentration measurement of TPGS-Gem micelles using methyl orange as hydrophobic probe, inflexion point in the graph represents the CMC value.

indicated high stability, which prevents its dissociation into unimers upon dilution with large blood volume.

3.1.7 In vitro drug release. The rate of gemcitabine release from TPGS-Gem micelles was evaluated in PBS buffer ( $\mathrm{pH}$ 7.4) at various temperatures $\left(30,37\right.$ and $\left.40{ }^{\circ} \mathrm{C}\right)$. As illustrated in Fig. 6 the release of gemcitabine from prodrug micelles showed significantly slower release at $30{ }^{\circ} \mathrm{C}$ than that at 37 and $40{ }^{\circ} \mathrm{C}$. However, a lower increment of drug release at temperature 40 ${ }^{\circ} \mathrm{C}$ was observed than that of drug release at $37{ }^{\circ} \mathrm{C}$. Under all temperatures the release of gemcitabine began as an initial slow release $\left(2.4 \%\right.$ at $30{ }^{\circ} \mathrm{C}, 8.5 \%$ at $37^{\circ} \mathrm{C}$ and $10 \%$ at $40{ }^{\circ} \mathrm{C}$ in $\left.1 \mathrm{~h}\right)$ followed by a continued sustained release and exhibited a similar release pattern at all the temperatures initially. The release of gemcitabine after $48 \mathrm{~h}$ was $38 \%$ at $30^{\circ} \mathrm{C}, 59 \%$ at $37^{\circ} \mathrm{C}$

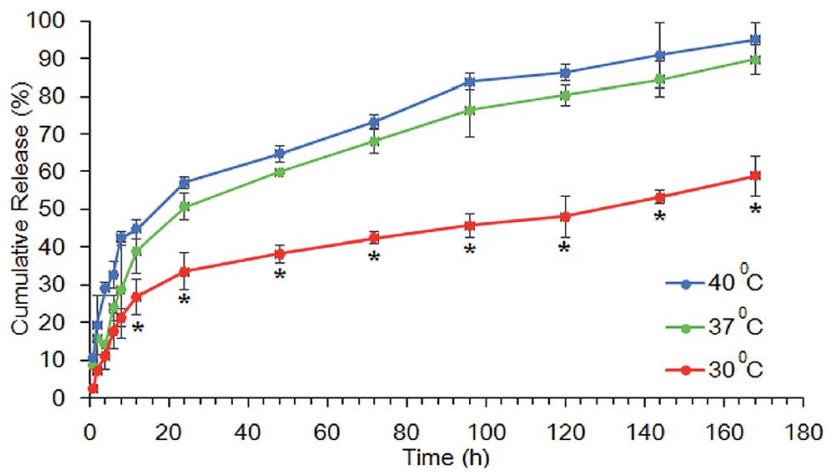

Fig. 6 Metabolic stability of TPGS-Gem micelles in comparison to native gemcitabine. Micellar gemcitabine or free gemcitabine $(0.4 \mathrm{mM})$ was incubated in a buffer ( $\mathrm{pH} 7.5)$ containing cytidine deaminase $(10 \mu \mathrm{l}$, specific activity 3.5 unit per $\mathrm{mg})$ at $37^{\circ} \mathrm{C}(* P<0.05, n=3)$. and $64 \%$ at $40{ }^{\circ} \mathrm{C}$ and a sustained released was observed subsequently. The accumulative release at one week was measured as $58 \%$ at $30{ }^{\circ} \mathrm{C}, 89 \%$ at $37{ }^{\circ} \mathrm{C}$ and $95 \%$ at $40{ }^{\circ} \mathrm{C}$. The drug release study demonstrated that TPGS-Gem micelles were able to sustain gemcitabine release at selected temperatures.

\subsection{Stability studies with cytidine deaminase}

After intravenous administration, gemcitabine undergoes extensive metabolism to its inactive form, either intracellular or extracellular, due to the activity of CDA. ${ }^{10}$ The stability of gemcitabine in the micellar formulation was investigated after incubation with crude CDA in comparison with parent gemcitabine. The concentration of drug was quantified at various time intervals using LC-MS/MS. As a function of incubation time with cytidine deaminase, the concentration of gemcitabine is shown in Fig. 7. The disappearance in the native gemcitabine was observed time-dependently and only around $11 \%$ of gemcitabine was detected after $30 \mathrm{~min}$ of incubation. Whereas, highly significant resistant was observed in the gemcitabine micellar formulation with more than $90 \%$ of gemcitabine can be detected after $30 \mathrm{~min}$ of incubation with crude CDA. This modest degradation of gemcitabine in TPGS-Gem micelles demonstrated the stability of formulation against CDA. These results are in accordance with previous reports, suggested that substitution of a $4-(N)$-amino group of gemcitabine prevents enzymatic degradation. ${ }^{20,47}$

\subsection{In vitro cytotoxicity}

The in vitro antiproliferative activity was performed by standard MTT assay after incubation of TPGS-Gem micelles, gemcitabine and placebo TPGS micelles with BxPC-3 cells as a model 


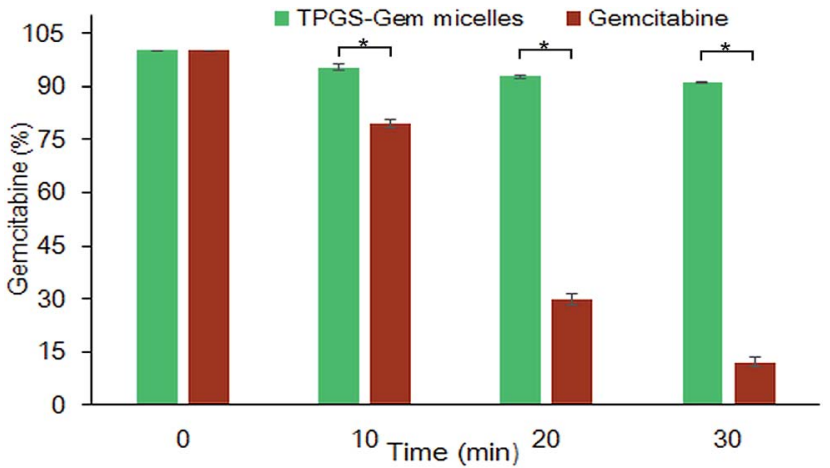

Fig. 7 Release profile of gemcitabine from TPGS-Gem micelles after incubation in PBS ( $\mathrm{pH}$ 7.4) for one week, at various temperatures i.e. 30,37 and $40{ }^{\circ} \mathrm{C}$. The concentration of drug released at specific time point was analyzed validated $\mathrm{HPLC}$ method $\left(* P<0.05,30^{\circ} \mathrm{C}\right.$ vs. $37^{\circ} \mathrm{C} /$ $40{ }^{\circ} \mathrm{C}$, after Bonferroni correction, $n=3$ ).

pancreatic cancer cell line at different incubation points i.e. 24 $\mathrm{h}, 48 \mathrm{~h}$, and $72 \mathrm{~h}$ (Fig. 8A-C respectively). Results suggested that the various test samples exhibited dose and time dependent cytotoxicity against BxPC-3 cells. It is noteworthy that placebo TPGS micelles also showed significant antiproliferative activity. The TPGS-Gem micelles and placebo TPGS micelles showed highly significant growth inhibition of BxPC- 3 cells after $24 \mathrm{~h}$ as compared to gemcitabine. The $\mathrm{IC}_{50}$ value of native gemcitabine was evaluated as $165 \pm 8.65 \mu \mathrm{M}$ at $24 \mathrm{~h}$ of incubation time while the $\mathrm{IC}_{50}$ value of TPGS-Gem micelles was $6.13 \pm 0.35 \mu \mathrm{M}$, and the $\mathrm{IC}_{50}$ value of the equivalent amount of placebo TPGS micelles was found to be $9.09 \pm 0.7 \mu \mathrm{M}$. Further, after $48 \mathrm{~h}$ of incubation with samples, a similar trend was observed and TPGS-Gem micelles showed a significant higher cytotoxicity as compared to gemcitabine, however, the $\mathrm{IC}_{50}$ value of gemcitabine decreased massively to $2.4 \pm 0.23 \mu \mathrm{M}$, and the $\mathrm{IC}_{50}$ value of TPGS-Gem micelles and placebo TPGS micelles was demonstrated as $1.6 \pm 0.26 \mu \mathrm{M}, 3.1 \pm 0.28 \mu \mathrm{M}$, respectively. A further extend in the incubation time to $72 \mathrm{~h}$, continued to decrease the drug concentration necessary to $50 \%$ of growth inhibition. The $\mathrm{IC}_{50}$ values were decreased to $0.27 \pm 0.1 \mu \mathrm{M}, 0.6 \pm 0.22 \mu \mathrm{M}$, and $1.76 \pm 0.22 \mu \mathrm{M}$ for gemcitabine, TPGS-Gem micelles, and placebo TPGS micelles respectively. However, there a comparable difference was showed in the $\mathrm{IC}_{50}$ value of gemcitabine and TPGS-Gem micelles after $72 \mathrm{~h}$ of incubation (Fig. 8D). The enhanced cytotoxic efficacy of gemcitabine could be due to the intrinsic anticancer efficacy of TPGS and/or stability of gemcitabine in micellar formulation against cytidine deaminase, which can convert the monophosphorylated form of gemcitabine to an inactive metabolite.

\subsection{Nucleoside transporter inhibition}

Due to the highly hydrophilic character of gemcitabine, it relies on the nucleoside transporter to cross the cellular lipid bilayer and display its antiproliferative activity. A resistance mechanism of gemcitabine includes deficiency of nucleoside transporters, causes decrease in the transport activity of drug into the cell. ${ }^{48}$ Therefore, to assess the dependency of TPGS-Gem micelles on nucleoside transporters like gemcitabine, a nucleoside transporter inhibition assay was performed. During MTT
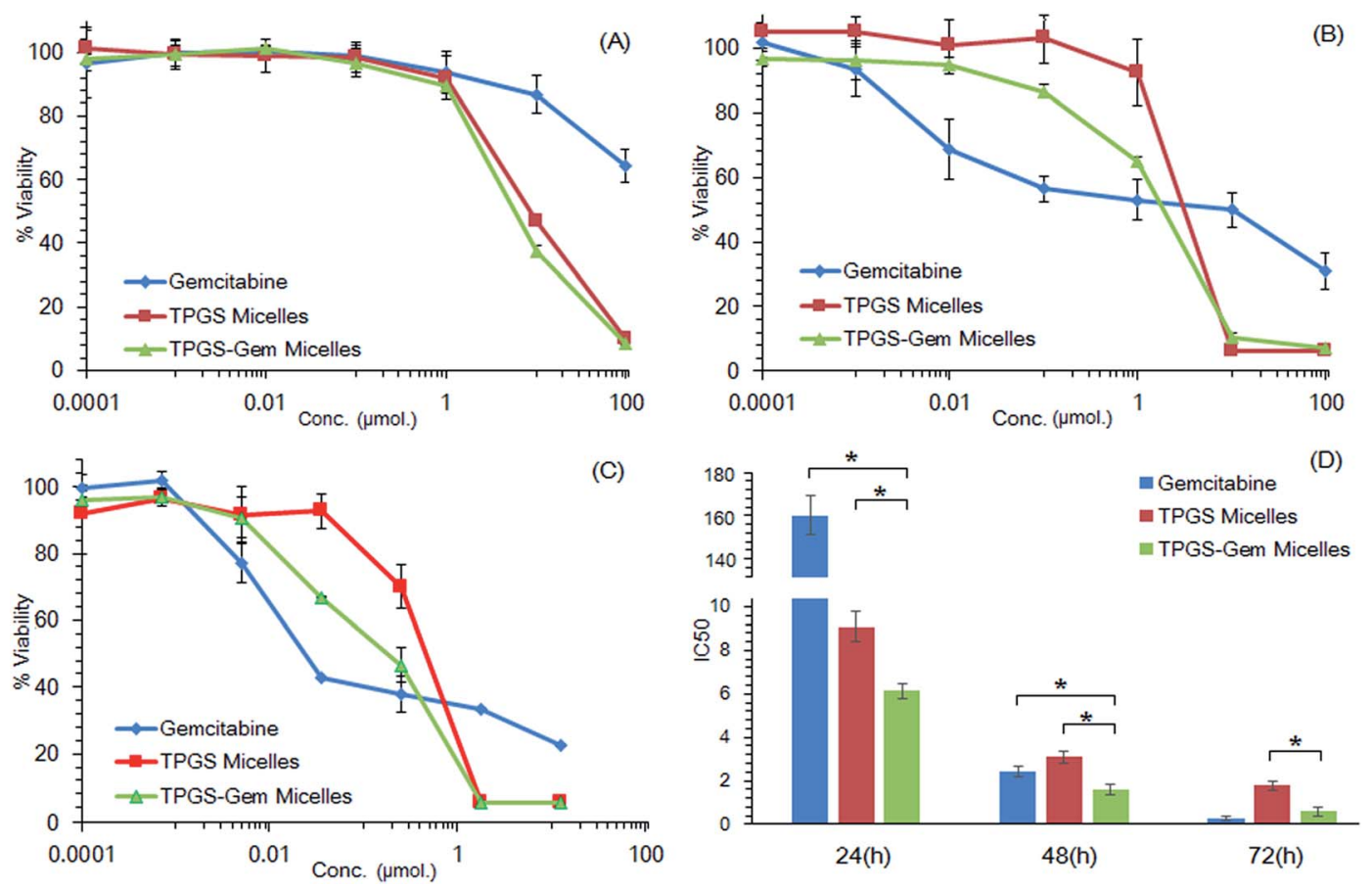

Fig. 8 Percent of cell viability on different concentrations of gemcitabine, TPGS-Gem micelles and placebo TPGS micelles (i.e. TPGS with no drug conjugated, at equivalent weight as in TPGS-Gem micelles) against BxPC-3 cells at incubation time $24 \mathrm{~h}(\mathrm{~A}), 48 \mathrm{~h}(\mathrm{~B})$ and $72 \mathrm{~h}(\mathrm{C})$. The IC $\mathrm{C}_{50}$ value obtained cells after incubation of samples at different time points (D). The results represent mean $S D$ of three experiments. $* P<0.05$ vs. gemcitabine/placebo TPGS micelles. 
assay, the cells were treated with dipyridamole, to block the nucleoside transporter, prior to addition of various concentration of TPGS-Gem micelles and gemcitabine. The $\mathrm{IC}_{50}$ values were determined against BxPC-3, pancreatic cancer cells after $48 \mathrm{~h}$ of incubation (Table 1 ). The $\mathrm{IC}_{50}$ value of native

Table 1 Effect of nucleoside transporter inhibitor on antiproliferative activity of gemcitabine and TPGS-Gem micelles against BxPC-3 cell lines following $48 \mathrm{~h}$ of incubation

\begin{tabular}{lrl}
\hline & \multicolumn{2}{c}{ BxPC-3 cells } \\
\cline { 2 - 3 } Sample & $\begin{array}{cl}\mathrm{IC}_{50} \\
(\mu \mathrm{M})\end{array}$ & $\begin{array}{l}\text { Relative gemcitabine } \\
\text { resistance }\end{array}$ \\
\hline Gemcitabine & 2.4 & - \\
Gemcitabine + dipyridamole & 11.9 & 5 \\
TPGS-Gem micelles & 1.6 & - \\
TPGS-Gem micelles + dipyridamole & 1.3 & 0.82
\end{tabular}

gemcitabine obtained after treatment with dipyridamole was 11 $\mu \mathrm{M}$, which is 5 -fold higher than the $\mathrm{IC}_{50}$ value obtained with the cell not treated with dipyridamole. However, when TPGS-Gem micelles were treated with cells pre-incubated with dipyridamole, there was no significant change was observed in the $\mathrm{IC}_{50}$ value. These results reflect that TPGS-Gem micelles were not dependent on nucleoside transporter to cross the cellular lipid bilayer.

\subsection{Cellular uptake}

The qualitative uptake of coumarin-6 loaded TPGS-Gem micelles in BxPC-3 cells was determined in the presence and absence of dipyridamole by measurement of fluorescence. Coumarin-6 was used as a fluorescent marker to identify the uptake of micelles in BxPC-3 cells. Fig. 9 shows the uptake of TPGS-Gem micelles after $4 \mathrm{~h}$ of incubation with BxPC-3 cells, the green fluorescence was due to the coumarin-6 loaded micelles internalized by the cells. In order to confirm that
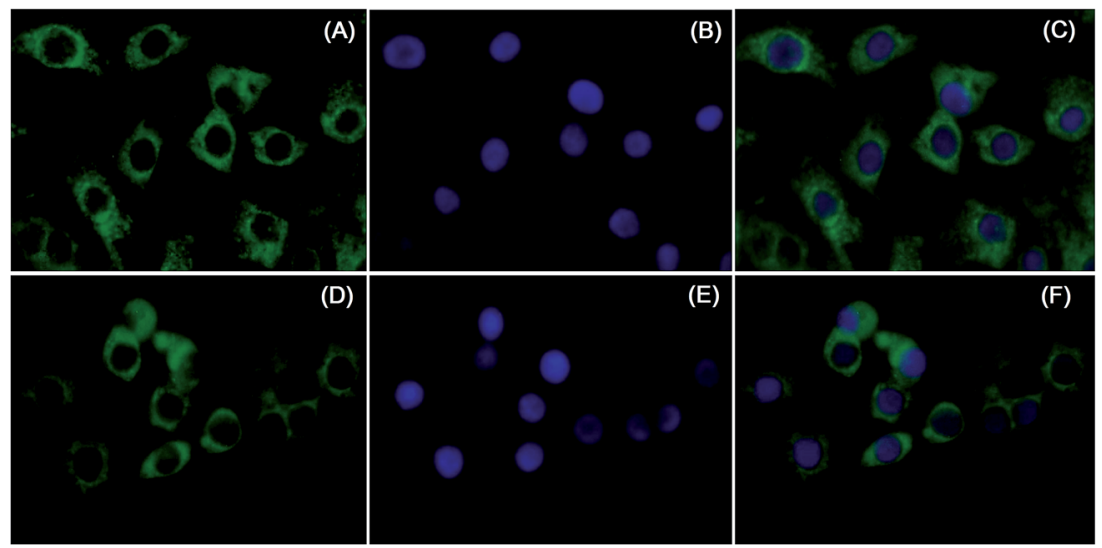

Fig. 9 Demonstration of cellular uptake of TPGS-Gem micelles using fluorescence microscopy in BxPC-3 cell lines in presence (A-C) and absence $(D-F)$ of nucleoside transporter, dipyridamole. Micelles up-taken by cells showing green fluorescence and nuclei stained by DAPI showing blue fluorescence. Images were captured using EVOS® Floid® cell imaging station.
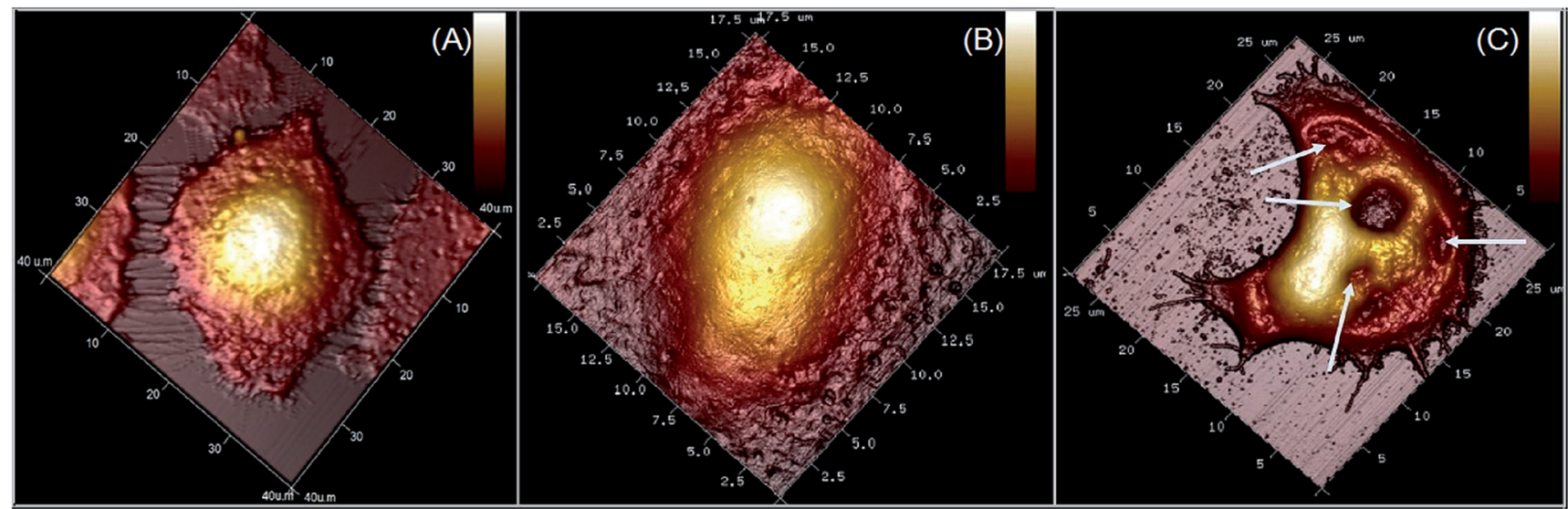

Fig. 10 Effect of gemcitabine and TPGS-Gem micelles on the cellular morphology in human pancreatic cancer cell line (BxPC-3) by AFM topography. The cells were treated with a $10 \mu \mathrm{M}$ concentration of test sample with respect to drug concentration in 6 well plates for $24 \mathrm{~h}$ and fixed by $2.5 \%$ of glutaraldehyde before images were captured under AFM. (A) Non-treated control cell, (B) cell treated with gemcitabine and (C) cell treated with TPGS-Gem micelles (arrow showing the pits on the surface of cell). 
fluorescence was present inside the cells, nucleus was counter stained with a DAPI, a blue fluorescent dye. The green fluorescence adjacent to the nucleus confirming the micelles were within the cells instead of attached to the cell surface. Furthermore, nearly all cells either in presence (Fig. 9A) and absence (Fig. 9D) of nucleoside transporter inhibitor were stained with green fluorescence suggesting that there was no significant difference in the uptake of micelles, suggesting that in the micellar formulation gemcitabine does not dependent on nucleoside transporters for internalization in the cells. These results can be correlated with the insignificant change in the $\mathrm{IC}_{50}$ values obtained after inhibition of nucleoside transporters by dipyridamole.

\subsection{AFM topography}

To study the morphological changes in BxPC-3 cells after treatment with TPGS-Gem micelles and native gemcitabine, the cells were observed under atomic force microscope (AFM). The control cells were treated with media only. It was observed that the control cell had a smooth well-defined morphology and showed an epithelial cell shape in general (Fig. 10A). The AFM image of cell treated with native gemcitabine showed a smooth surface, however, marked specific degenerative alteration in the cell shape can be easily observed in the image (Fig. 10B). This could be correlated with the higher $\mathrm{IC}_{50}$ value of the gemcitabine after $24 \mathrm{~h}$ of incubation. Instead, in the AFM image of TPGS-Gem micelles treated cell, several pits on the surface is clearly visible and the morphology of cell was also transformed (Fig. 10C). The small pits on the cells attributed the morphological alteration in response to TPGS-Gem micelles. ${ }^{49}$ The ability to visualize cellular state is advantageous in order to accurately demonstrate the effect of these formulations on the morphology and physiology. Although not qualitative these provide a good tool to compliment the cytotoxicity studies and provide insight into the likely fate of the cells. In this study the presence of pitting indicated that cellular morphology has been altered and perhaps cell membrane integrity has been compromised. This indicates that the cells are not residing in their 'normal' state. Hence, the observations of AFM topography suggested the enhanced efficacy of gemcitabine after formation of TPGS conjugated micelles.

\section{Conclusion}

In the present investigation, TPGS-Gem prodrug was synthesized and thoroughly characterised using analytical techniques. The micelles of TPGS-Gem prodrug were prepared and characterised for various physicochemical properties. The TPGSGem micelles were evaluated against the determinants, which hamper gemcitabine activity. The significant resistance of prepared micelles was observed against cytidine deaminase which may lead to long circulation half-life of gemcitabine. The prepared gemcitabine micelles exhibited enhanced anticancer activity in the selected cell lines as compared to free gemcitabine. It is remarkable that unlike gemcitabine, TPGS-Gem micelles were not relying on nucleoside transporter to cross the cellular lipid bilayer. Further, morphological studies suggested the potential anticancer activity of TPGS-Gem micelles in vitro. Moreover, our findings provide a guideline for in vivo investigations to confirm the feasibility of micellar formulation for clinics.

\section{Acknowledgements}

We are grateful to Institute of Science and Technology in Medicine and School of Pharmacy, Keele University for providing necessary facilities for carrying out this work. The financial assistance provided by British Council and Department of Science and Technology, India as a Newton-Bhabha fellowship to Vaibhav Khare is gratefully acknowledged (DST/ INSPIRE/NBHF/2014/25).

\section{References}

1 M. Hidalgo, N. Engl. J. Med., 2010, 362, 1605-1617.

2 K. D. Lillemoe, Ann. Surg., 1995, 221, 133-148.

3 D. Li, K. Xie, R. Wolff and J. L. Abbruzzese, Lancet, 2004, 363, 1049-1057.

4 V. Heinemann, Semin. Oncol., 2002, 29, 25-35.

5 M. Di Marco, R. Di Cicilia, M. Macchini, E. Nobili, S. Vecchiarelli, G. Brandi and G. Biasco, Oncol. Rep., 2010, 23, 1183-1192.

6 J. Ciccolini, C. Serdjebi, G. J. Peters and E. Giovannetti, Cancer Chemother. Pharmacol., 2016, 1-12.

7 S. A. Welch and M. J. Moore, J. Clin. Oncol., 2007, 25, 21592161.

8 V. Khare, N. Alam, A. Saneja, R. D. Dubey and P. N. Gupta, J. Biomed. Nanotechnol., 2014, 10, 3462-3482.

9 S. Ali, A. Ahmad, S. Banerjee, S. Padhye, K. Dominiak, J. M. Schaffert, Z. Wang, P. A. Philip and F. H. Sarkar, Cancer Res., 2010, 70, 3606-3617.

10 J. L. Abbruzzese, R. Grunewald, E. A. Weeks, D. Gravel, T. Adams, B. Nowak, S. Mineishi, P. Tarassoff, W. Satterlee, M. N. Raber, et al., J. Clin. Oncol., 1991, 9, 491-498.

11 S. Aggarwal, S. Gupta, D. Pabla and R. S. Murthy, Cancer Nanotechnol., 2013, 4, 145-157.

12 J. L. Arias, L. H. Reddy and P. Couvreur, J. Drug Targeting, 2009, 17, 586-598.

13 M. L. Immordino, P. Brusa, F. Rocco, S. Arpicco, M. Ceruti and L. Cattel, J. Controlled Release, 2004, 100, 331-346.

14 C. Bornmann, R. Graeser, N. Esser, V. Ziroli, P. Jantscheff, T. Keck, C. Unger, U. T. Hopt, U. Adam, C. Schaechtele, U. Massing and E. von Dobschuetz, Cancer Chemother. Pharmacol., 2008, 61, 395-405.

15 Z. Daman, S. Ostad, M. Amini and K. Gilani, Int. J. Pharm., 2014, 468, 142-151.

16 S. Zhu, P. Wonganan, P. D. Lansakara, H. L. O'Mary, Y. Li and Z. Cui, Biomaterials, 2013, 34, 2327-2339.

17 V. Khare, S. Kour, N. Alam, R. D. Dubey, A. Saneja, M. Koul, A. P. Gupta, D. Singh, S. K. Singh, A. K. Saxena and P. N. Gupta, Int. J. Pharm., 2014, 470, 51-62. 
18 M. Vandana and S. K. Sahoo, Biomaterials, 2010, 31, 93409356.

19 L. V. Kiew, S. K. Cheong, K. Sidik and L. Y. Chung, Int. J. Pharm., 2010, 391, 212-220.

20 X. M. Tao, J. C. Wang, J. B. Wang, Q. Feng, S. Y. Gao, L. R. Zhang and Q. Zhang, Eur. J. Pharm. Biopharm., 2012, 82, 401-409.

21 P. Couvreur, B. Stella, L. H. Reddy, H. Hillaireau, C. Dubernet, D. Desmaele, S. Lepetre-Mouelhi, F. Rocco, N. Dereuddre-Bosquet, P. Clayette, V. Rosilio, V. Marsaud, J. M. Renoir and L. Cattel, Nano Lett., 2006, 6, 2544-2548.

22 D. Chitkara, A. Mittal, S. W. Behrman, N. Kumar and R. I. Mahato, Bioconjugate Chem., 2013, 24, 1161-1173.

23 H. Han, H. Wang, Y. Chen, Z. Li, Y. Wang, Q. Jin and J. Ji, Nanoscale, 2016, 8, 283-291.

24 Z. Zhang, S. Tan and S. S. Feng, Biomaterials, 2012, 33, 48894906.

25 H. Borowy-Borowski, C. Sodja, J. Docherty, P. R. Walker and M. Sikorska, J. Drug Targeting, 2004, 12, 415-424.

26 R. J. Sokol, N. Butler-Simon, C. Conner, J. E. Heubi, F. R. Sinatra, F. J. Suchy, M. B. Heyman, J. Perrault, R. J. Rothbaum, J. Levy, et al., Gastroenterology, 1993, 104, 1727-1735.

27 C. M. Neophytou, C. Constantinou, P. Papageorgis and A. I. Constantinou, Biochem. Pharmacol., 2014, 89, 31-42.

28 H. J. Youk, E. Lee, M. K. Choi, Y. J. Lee, J. H. Chung, S. H. Kim, C. H. Lee and S. J. Lim, J. Controlled Release, 2005, 107, 43-52.

29 Y. Mi, Y. Liu and S. S. Feng, Biomaterials, 2011, 32, 40584066.

30 P. Xu, Q. Yin, J. Shen, L. Chen, H. Yu, Z. Zhang and Y. Li, Int. J. Pharm., 2013, 454, 21-30.

31 C. Constantinou, A. Papas and A. I. Constantinou, Int. J. Cancer, 2008, 123, 739-752.

32 Q. Guo, Y. Chen, B. Zhang, M. Kang, Q. Xie and Y. Wu, Biochem. Pharmacol., 2009, 77, 1674-1683.
33 W. S. Liu, H. J. Yan, R. Y. Qin, R. Tian, M. Wang, J. X. Jiang, M. Shen and C. J. Shi, Dig. Dis. Sci., 2009, 54, 89-96.

34 Y. Guo, M. Chu, S. Tan, S. Zhao, H. Liu, B. O. Otieno, X. Yang, C. Xu and Z. Zhang, Mol. Pharm., 2014, 11, 59-70.

35 G. Cavallaro, M. Licciardi, S. Salmaso, P. Caliceti and G. Gaetano, Int. J. Pharm., 2006, 307, 258-269.

36 S. Sheng, T. Zhang, S. Li, J. Wei, G. Xu, T. Sun, Y. Chen, F. Lu, Y. Li and J. Yang, RSC Adv., 2015, 5, 53846-53856.

37 I. F. Uchegbu, L. Sadiq, M. Arastoo, A. I. Gray, W. Wang, R. D. Waigh and A. G. Schatzlein, Int. J. Pharm., 2001, 224, 185-199.

38 V. L. Damaraju, S. Damaraju, J. D. Young, S. A. Baldwin, J. Mackey, M. B. Sawyer and C. E. Cass, Oncogene, 2003, 22, 7524-7536.

39 H. Kulhari, D. Pooja, S. Shrivastava, S. R. Telukutala, A. K. Barui, C. R. Patra, G. M. N. Vegi, D. J. Adams and R. Sistla, Nanomedicine, 2015, 11, 1511-1520.

40 C. Maurizio, R. Flavio and T. Elena, New J. Chem., 2015, 39, 3484-3496.

41 E. Blanco, C. W. Kessinger, B. D. Sumer and J. Gao, Exp. Biol. Med., 2009, 234, 123-131.

42 V. Prabhu, S. Uzzaman, V. M. B. Grace and C. Guruvayoorappan, J. Cancer Ther., 2011, 2, 325-334.

43 S. Acharya and S. K. Sahoo, Adv. Drug Delivery Rev., 2011, 63, 170-183.

44 Y. Mi, J. Zhao and S. S. Feng, Int. J. Pharm., 2012, 438, 98-106. 45 P. K. T. Lin, W. P. Cheng and C. Hoskins, US Pat., 0238487, 2012.

46 P. P. Constantinides, J. Han and S. S. Davis, Pharm. Res., 2006, 23, 243-255.

47 X. Song, P. L. Lorenzi, C. P. Landowski, B. S. Vig, J. M. Hilfinger and G. L. Amidon, Mol. Pharmaceutics, 2005, 2, 157-167.

48 A. M. Bergman, H. M. Pinedo and G. J. Peters, Drug Resist. Updates, 2002, 5, 19-33.

49 C. Hoskins, A. Cuschieri and L. Wang, J. Nanobiotechnol., 2012, 10, 15. 